\title{
Influence of Computer Clipboard Transfer of Image Data on Print Quality Perception and Measurement
}

\author{
Ivan PUČIĆ, Mile MATIJEVIĆ, Nikola MRVAC
}

\begin{abstract}
In today's virtual environment transfer of data within the system is a necessary and standard operation. Computer clipboard is one of the common data transfer methods. This paper tests the changes in image data during the transfer from one program to another. Computer programs and systems use different standards, which causes changes in colour values due to different image standards used by programs and systems. Each transfer between programs causes adaptation of image data to new program standards. That shift is visible on images from inside the system. The difference grows even more on the printed sample. Calibration strip and photographs were used as research elements. Calibration strip was generated in Monaco Profiler. The analysis was performed on measured numerical values, and it showed significant colour changes in samples. The visual research was made on printed photo samples and has shown that the visibility of colour changes more or less depends on the motif type.
\end{abstract}

Keywords: clipboard; colour systems; graphic tools; operating system

\section{INTRODUCTION}

Technology development caused the narrow integration of today's printing industry and informatic systems. Today's information transfer systems are in principle formatted for the specific medium at the end of production [1, 2]. Data transfer between computer systems and direct import of files in the software does not show changes in numerical values of data unless the user determines the adjustments at the import.

Increasing integration of multiple systems leads to the increased need for synchronicity of all system parts including those not previously used in all ways they supported. The use of clipboard for data transfer is a standard working procedure. Clipboard was not used for image transfer in the graphic industry as a standard tool and no measurements were made. Data is always adapted to the new space it enters unless the program buffers are identical.

By using the operating system as a medium for data transfer between prepress programs the information is translated as following: source program - operating system - destination program. Transfer of data between different programs includes the changes of used standards and causes adaptation of image data from start to destination program. Adaptation causes the change in colour values which influences the quality and perception of image data both in print and on screen.

The purpose of this paper is to examine the change of colour in all available production steps by defining test strips and measuring them in pdf and printed sample.

\section{CLIPBOARD IN THE OPERATING SYSTEM}

Clipboard is a part of the operating system used for temporary data storage and transfer within single or multiple computer programs. Memory object can be in any, so called, clipboard format [3](Tab. 1). All computer systems use multiple data formats:

- standard formats are defined in the operating system (in this case Microsoft Windows)

- registered formats are created by each program to prevent data loss
- Private formats are used only inside the creator program and are erased from the system when the program is turned off.

Transfer between programs causes the adaptation of data to the standard of destination program which causes the change of colour values. Direct transfer is only possible between compatible programs. Others need to be translated into the system and then to the destination format. Textual data may be changed in used font, colour etc. depending on the standards used by source and destination program [4]. The change in textual data also appears due to the style adjustment to the destination program (Fig. 1). Data is input into the clipboard in multiple standards, which improves the possibility of correct transfer of data between programs.

The transfer of image data causes the adaptation of colour values.

Table 1 Some of the data formats for the transfer of image information in Microsoft Windows operating system [4]

\begin{tabular}{|l|l|}
\hline Constant values & Description \\
\hline 8 & $\begin{array}{l}\text { A memory object containing a } \\
\text { BITMAPINFO structure followed by } \\
\text { the bitmap bits. }\end{array}$ \\
\hline $\begin{array}{l}\text { CF_DIBV5 } \\
17\end{array}$ & $\begin{array}{l}\text { A memory object containing a } \\
\text { BITMAPV5HEADER structure } \\
\text { followed by the bitmap color space } \\
\text { information and the bitmap bits. }\end{array}$ \\
\hline $\begin{array}{l}\text { CF_DSPBITMAP } \\
\text { 0x0082 }\end{array}$ & $\begin{array}{l}\text { Bitmap display format associated } \\
\text { with a private format. }\end{array}$ \\
\hline CF_DSPENHMETAFILE & $\begin{array}{l}\text { Enhanced metafile display format } \\
\text { associated with a private format. }\end{array}$ \\
\hline $\begin{array}{l}\text { CF_DSPMETAFILEPICT } \\
\text { 0x0083 }\end{array}$ & $\begin{array}{l}\text { Metafile-picture display format } \\
\text { associated with a private format. }\end{array}$ \\
\hline $\begin{array}{l}\text { CF_METAFILEPICT } \\
3\end{array}$ & $\begin{array}{l}\text { Handle to a metafile picture format } \\
\text { as defined by the METAFILEPICT } \\
\text { structure. }\end{array}$ \\
\hline $\begin{array}{l}\text { CF_PALETTE } \\
9\end{array}$ & $\begin{array}{l}\text { Handle to a colour palette. Whenever } \\
\text { an application places data in the } \\
\text { clipboard that depends on or } \\
\text { assumes a colour palette, it should } \\
\text { place the palette on the clipboard as } \\
\text { well. }\end{array}$ \\
\hline $\begin{array}{l}\text { CF_TIFF } \\
6\end{array}$ & $\begin{array}{l}\text { Tagged-image file format. } \\
\text { and }\end{array}$ \\
\hline
\end{tabular}




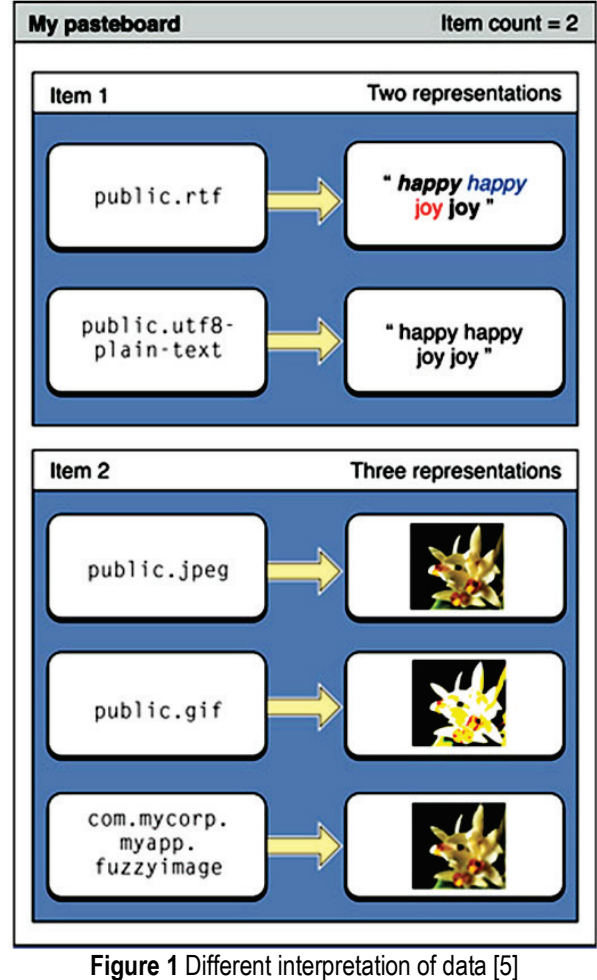

Clipboard itself has multiple purposes [6]:

- most noticeable is copy-paste function "drag and drop". Selection of data and their dragging transfers the data into the clipboard. The program uses the data from the clipboard and processes them in it.

- a simple function is enhanced by the possibility of different data representation (Tab. 1), which enhances the complexity of the system.

\section{EXPERIMENTAL PART}

Experimental part attempts to determine the influence of clipboard on numerical colour values in the image and the influence of those changes on visual perception of image samples.

\subsection{Research Description}

Prepress software on Microsoft Windows operating system was used to investigate the colour change in image documents.

This research attempts to determine the level of numerical colour values change and the influence of the change on visual perception of processed images in comparison to the original documents.

All program settings were left on default settings, as the intention was to view the changes in the standard system. No colour settings were altered for this research. The original document was created as tif (tagged image format) without embedded profiles.

Data transfer was performed between Adobe Photoshop, Adobe Illustrator, Adobe Indesign, Corel Draw and Corel Photopaint, as stated in Tab. 2.

Experimental research consists of two parts. Instrumental measures the numerical change in colour values and visual compares colour changes seen by the human observer.
Table 2 Direction of image data transfer

\begin{tabular}{|l|l|}
\hline \multicolumn{1}{|c|}{ Source program } & \multicolumn{1}{c|}{ Destination program } \\
\hline Corel Draw X7 & Adobe Illustrator CC \\
\hline Corel Draw X7 & Adobe Indesign CC \\
\hline Corel Draw X7 & Adobe Photoshop CC \\
\hline Adobe Illustrator CC & Corel Draw X7 \\
\hline Adobe Illustrator CC & Adobe Indesign CC \\
\hline Adobe Illustrator CC & Adobe Photoshop CC \\
\hline Corel Photopaint X7 & Adobe Indesign CC \\
\hline Corel Photopaint X7 & Adobe Photoshop CC \\
\hline Adobe Photoshop CC & Corel Draw X7 \\
\hline Adobe Photoshop CC & Adobe Indesign CC \\
\hline Adobe Photoshop CC & Adobe Illustrator CC \\
\hline Adobe Photoshop CC & Corel Photopaint X7 \\
\hline
\end{tabular}

The experimental part consists of two measurements. The first is performed in the operating system with ChromiX Color Think software. The second part is performed on printed samples.

The original document consists of calibration stripe generated in Monaco Profiler (Fig. 2a). It is designed for automatic measurement with a spectrophotometer.

The original is placed in the source program and transferred in destination programs with a clipboard. No colour of clipboard standards was performed. Only standard settings were used.

Pdf document was made from destination programs and measured with ChromiX Color Think software. Measured Lab values were used for first part of the measurement and are the first measurement before printing of the samples. Gained values give the first $\Delta \mathrm{E}_{00}$ values as the result of numerical colour change caused by clipboard transfer. Those values give real changes in colour made within the operating system.

Printed pdf document was printed on Xerox DC700 printer. Samples were measured with spectrophotometer X-rite DTP 41 and program Monaco Profiler. Measured values were used to calculate the second $\Delta E_{00}$.

Colour change $\Delta E_{00}$ is calculated with the formula [7]:

$\Delta E_{00}=\left[\left(\frac{\Delta L^{\prime}}{k_{L} S_{L}}\right)^{2}+\left(\frac{\Delta C_{a b}^{\prime}}{k_{C} S_{C}}\right)^{2}+\left(\frac{\Delta H_{a b}^{\prime}}{k_{H} S_{H}}\right)^{2}+R_{T}\left(\frac{\Delta C_{a b}^{\prime}}{k_{C} S_{C}}\right)\left(\frac{\Delta H_{a b}^{\prime}}{k_{H} S_{H}}\right)\right]^{0.5}$

Values calculated with $\Delta E_{00}$ formula are graded using Tab. 3 [8].

Table 3 Valuing of colorimetric colour difference for standard observer

\begin{tabular}{|l|l|}
\hline$\Delta E^{*}<0.2$ & no visual deviation \\
\hline$\Delta E^{*}=(0.2-1)$ & small visual deviation \\
\hline$\Delta E^{*}=(1-3)$ & acceptable visual deviation \\
\hline$\Delta E^{*}=(3-6)$ & still acceptable visual deviation \\
\hline$\Delta E^{*}>6$ & inacceptable visual deviation \\
\hline
\end{tabular}

Seven image originals (Fig. 2b) were selected for visual research. Originals were chosen according to prevailing colours on the motifs. Motifs with different prevailing colours were chosen in order to view deviation in different colouring. 


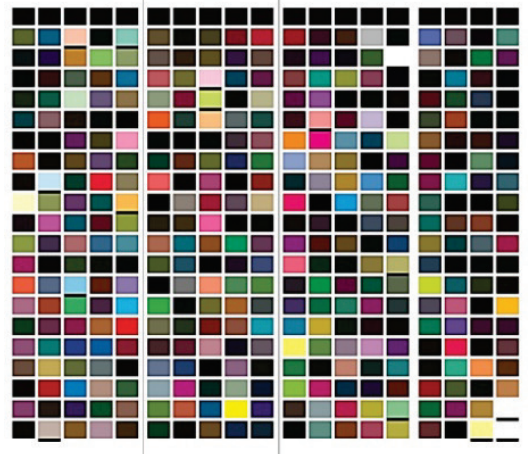

a) Test form for instrumental measurement
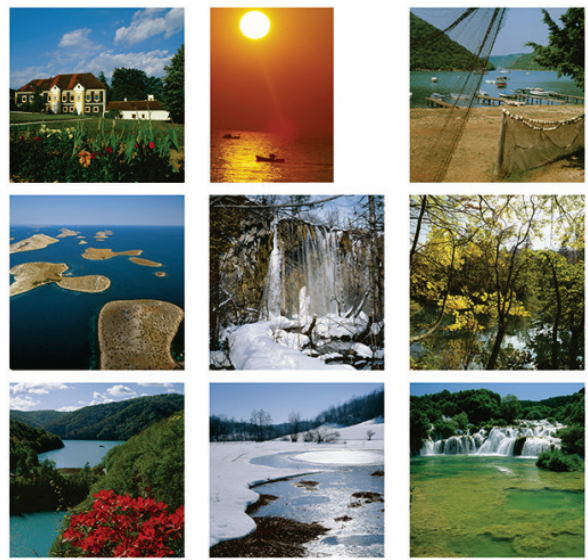

b) Test form for visual measurement Figure 2 Test form

\subsection{Definition of Test Form}

Test form consisting of two parts was created for the research (Fig. 2). One part was made for instrumental (Fig. 2a), and the other for visual research (Fig. 2b)

Starting document for both researches was made as tiff in CMYK color mode. CMYK was used because it is the standard colour model in the printing industry.

\subsection{Test form Printing}

Sample print was made on Xerox DC700 printer. The paper used for print was $250 \mathrm{gm}^{-2}$ coated Sappi Magno Satin and was conditioned in the print room for 48 hours under standard condition $\left(23{ }^{\circ} \mathrm{C}\right.$ temperature and relative humidity of $55 \%$ ).

\subsection{Instrumental Analysis}

Sample measurement was made with X-Rite DTP 41 reflex spectrometer in valve length from 390 to $710 \mathrm{~nm}$, with light source Gas Pressure @ $2850^{\circ} \mathrm{K}, 10 \mathrm{~nm}$ step and measuring geometry $45^{\circ} / 0^{\circ}$. In order to enhance statistical accuracy, each sample was measured on 10 samples.

\subsection{Visual Analysis}

Visual analysis of test samples was performed on 18 people of the mixed population of 30 years of age on average. All respondents passed Ishihara.
Visual evaluation of psychophysical part of the experiment was performed in standard viewing conditions for printing industry $\left(10^{\circ}\right.$ viewing angle, distance of observer to sample $60 \mathrm{~cm}$, natural matte gray surroundings, light 150 lux at $5400 \div 6000 \mathrm{~K}$ ).

A method of simultaneous binocular alignment will be used for visual part of the research. The comparison will be made with the original and the test sample placed side by side in the visual field. Each subject will have to align the samples in similarity to the original. Time is not limited.

The described method is the method of constant stimuli where stimuli samples are presented to the subject with different physical values.

Samples for the visual part of the research were selected based on the instrumental analysis in Tab. 4.

\begin{tabular}{|c|l|}
\multicolumn{2}{|l}{ Table 4 Selected samples } \\
\hline Sample number & \multicolumn{1}{c|}{ Transfer direction } \\
\hline 1 & Photoshop into Illustrator \\
\hline 2 & $\begin{array}{l}\text { Photoshop into Indesign } \\
\text { Illustrator into Corel Draw } \\
\text { Photoshop into Corel Draw }\end{array}$ \\
\hline 3 & Photo paint into Photoshop \\
\hline 4 & $\begin{array}{l}\text { Photo paint into Indesign } \\
\text { Illustrator into Photoshop } \\
\text { Illustrator into Indesign }\end{array}$ \\
\hline 5 & Corel Draw into Photoshop \\
\hline 6 & Corel Draw into Indesign \\
\hline 7 & Corel Draw into Illustrator \\
\hline 8 & Photoshop into Photopaint \\
\hline
\end{tabular}

Seven motifs were selected. Six had a dominant colour, and the seventh was a human face. Each subject had to determine samples closest to the original for all seven sets.

\section{RESULTS AND DISCUSSION \\ 4.1 Results of Instrumental Analysis}

Average $\Delta E_{00}$ was measured for each measured calibration stripe. $\Delta E_{00}$ values were also measured from destination pdfs and printed samples as shown in Tab. 5 .

Created pdf document was measured with colour picker. Is was confirmed that the CMYK values are the same as the original in the following samples: Photopaint in Indesign, Illustrator in Photoshop and Illustrator in Indesign. The difference in $\Delta E_{00}$ was up to 1,57 (Tab. 5). which also marks the level of change in print on the printing machine.

Once the samples equal to the original were excluded it was visible that $\Delta E_{00}$ is usually above 5 . This shows the high visibility of colour difference in samples.

Fig. 3 and 4 show the colour shift from the original to the sample. Ideally, the dots of the original and the sample would match. Figs. 3 and 4 show large shift and no common factor for the development of movement pattern sample.

Display of the colour changes in Fig. 3 was visualized in colour analysis software Chromix ColorThink in 2D view. Fig. 3a shows colour changes on the printed sample. Fig. $3 b$ shows the colour change in apdf document. The original and sample documents were compared. The end 
point of each shift is marked with the dot on the end of the line.

Table 5 Average $\Delta E_{00}$ measured for each sample in pdf documents and the printed samples

\begin{tabular}{|c|c|c|c|}
\hline $\begin{array}{l}\text { Destination to } \\
\text { target program }\end{array}$ & $\begin{array}{c}\Delta E_{00} \text { measured } \\
\text { from print }\end{array}$ & $\begin{array}{c}\Delta E_{00} \text { measured } \\
\text { from pdf } \\
\text { document }\end{array}$ & $\begin{array}{c}\text { Difference in } \\
\Delta E_{00} \text { values }\end{array}$ \\
\hline $\begin{array}{l}\text { Photoshop in } \\
\text { Illustrator }\end{array}$ & 2,8129631316 & 2,2357402303 & 0,5772229013 \\
\hline $\begin{array}{l}\text { Photoshop in } \\
\text { Indesign }\end{array}$ & 5,5137308077 & 6,0970499576 & 0,5833191499 \\
\hline $\begin{array}{l}\text { Photoshop in } \\
\text { Corel Draw }\end{array}$ & 5,4941775513 & 6,1032853553 & 0,609107804 \\
\hline $\begin{array}{l}\text { Photopaint in } \\
\text { Photoshop }\end{array}$ & 5,0413339848 & 3,8933578907 & 1,1479760941 \\
\hline $\begin{array}{l}\text { Photopaint in } \\
\text { Indesign }\end{array}$ & 1,30762958 & 0,0923133102 & 1,2153162698 \\
\hline $\begin{array}{l}\text { Illustrator in } \\
\text { Photoshop }\end{array}$ & 1,5758191581 & 0 & 1,5758191581 \\
\hline $\begin{array}{c}\text { Illustrator in } \\
\text { Indesign }\end{array}$ & 1,2610539971 & 0,0923133102 & 1,1687406869 \\
\hline $\begin{array}{l}\text { Illustrator in } \\
\text { Corel Draw }\end{array}$ & 5,4927144588 & 6,0666949717 & 0,5739805129 \\
\hline $\begin{array}{c}\text { Corel Draw in } \\
\text { Photoshop }\end{array}$ & 4,2235323054 & 3,2796740129 & 0,9438582925 \\
\hline $\begin{array}{c}\text { Corel Draw in } \\
\text { Indesign }\end{array}$ & 5,7794304514 & 4,5354229619 & 1,2440074895 \\
\hline $\begin{array}{c}\text { Corel Draw in } \\
\text { Illustrator }\end{array}$ & 5,9392373658 & 5,7407295356 & 0,1985078302 \\
\hline $\begin{array}{l}\text { Photoshop in } \\
\text { Photopaint }\end{array}$ & 5,2327743585 & 5,4262971101 & 0,1935227516 \\
\hline
\end{tabular}

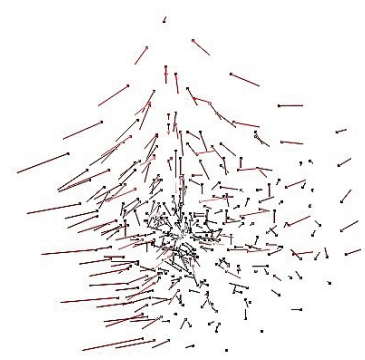

a)

Figure 3 The shift in colour values

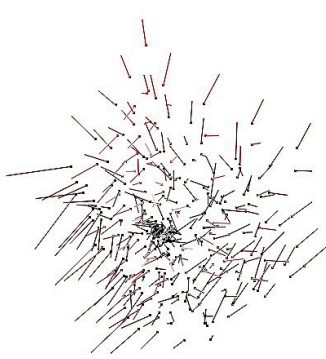

b)

Ideal conditions which are not possible to be achieved are visible in Fig. 4a (sample "Pdf Corel Photopaint to Adobe Indesign"). Even if all the programs and operating systems worked by the same standards, it is not possible to remove colour gain in print. It is possible to reduce the colour gain. Therefore, it is not possible to achieve ideal conditions and create an ideal print.

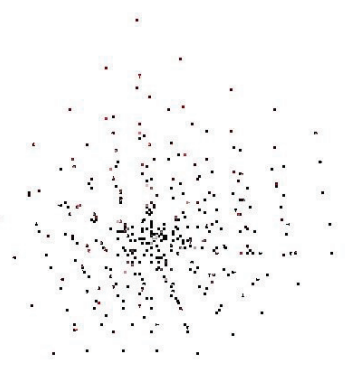

a)

Figure 4 Colour change in print
It is possible to measure great differences in measured values between the original and reproduction. However, in order to determine the real perception of quality loss in printed product, it is necessary to perform visual research.

\subsection{Visual Results}

The photograph of the face (Fig. 5) shows that the photos can be split into two groups. The first group shows reduced contrast and low saturation and the second shows higher saturation than the original.
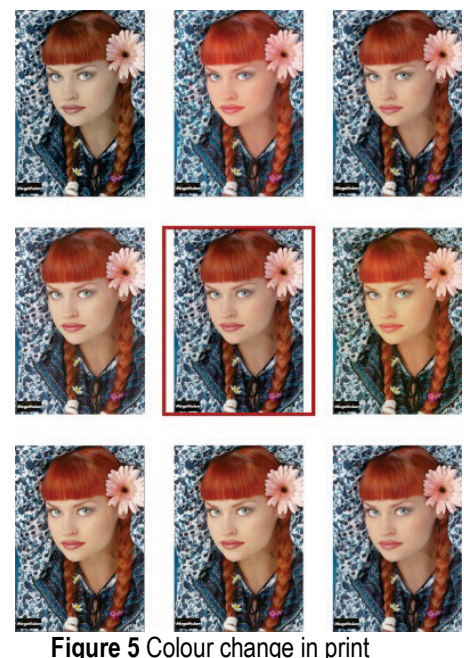

Subjects chose the reproduction closest to the original relatively fast and easy (Tab. 6). However, selecting other reproductions showed as a problem, considering their great differences from the original (Tab. 7).

Using similarity to grade quality of reproduction to the original is hard due to the mutual influence of all image elements on the perception of the image.

Table 6 Samples closest to the original

\begin{tabular}{|c|c|c|c|c|c|c|c|c|}
\hline \multirow{2}{*}{ Motif } & \multicolumn{7}{|c|}{ Sample } \\
\cline { 2 - 9 } & 1 & 2 & 3 & 4 & 5 & 6 & 7 & 8 \\
\hline 1 & 5 & 1 & & 9 & & & & 1 \\
\hline 2 & 6 & & & 12 & & & & \\
\hline 3 & 7 & 3 & & 1 & 8 & & & \\
\hline 4 & 6 & 1 & & 2 & 5 & & & 3 \\
\hline 5 & 5 & & & 3 & 6 & 3 & & \\
\hline 6 & 4 & 2 & & 7 & & & & 4 \\
\hline 7 & 10 & & & 6 & & & & 2 \\
\hline TOTAL & 44 & 7 & & 40 & 19 & 3 & & 10 \\
\hline
\end{tabular}

Table 7 Samples farthest from the original

\begin{tabular}{|c|c|c|c|c|c|c|c|c|}
\hline \multirow{2}{*}{ Motif } & \multicolumn{7}{|c|}{ Sample } \\
\cline { 2 - 9 } & 1 & 2 & 3 & 4 & 5 & 6 & 7 & 8 \\
\hline 1 & & 3 & 4 & & & & 6 & \\
\hline 2 & & 5 & & & & & 10 & \\
\hline 3 & & & 7 & & & 3 & & \\
\hline 4 & & & 13 & & & & 3 & 1 \\
\hline 5 & & & 9 & & & 1 & & 4 \\
\hline 6 & & & 10 & & & & 4 & 3 \\
\hline 7 & & 4 & 12 & & 2 & & & \\
\hline TOTAL & & 12 & 55 & & 2 & 4 & 23 & 8 \\
\hline
\end{tabular}

Two samples showed as best defined samples. Sample 1 (Adobe Photoshop into Adobe Illustrator) and Sample 4 (Corel Photopaint into Adobe Indesign; Adobe 
Illustrator into Adobe Photoshop; Adobe Illustrator into Adobe Indesign).

While the best results showed two closest samples, worst results came from Sample 4 (Photopaint into Photoshop).

Synthesis of the results tries to answer the question whether this way of work is appropriate for the graphic industry in regard to the increasing demand of modern society for higher quality and standards.

Instrumental analysis showed relatively large differences in colour change. Changes appear on saturation and a shift of colour towards another. For example, a shade of green can become more bluish.

Different motifs showed different results. In most cases, subjects expect that the sea is blue based on their experiences. Based on their experience and other influences they mostly conclude that the reproduction is good, even though it can significantly differ from the original.

It is usually easy for the subjects to determine the difference between the original and reproduction, but harder to describe that difference.

\section{CONCLUSION}

The use of clipboard is a routine operation in the modern graphic industry. However, its usage can cause a number of problems which can result in lower quality of the product. In most cases, those problems appear in regard to the usage of different graphic tools. They are dependent on the type of data being transferred through the clipboard, tools themselves and the data transfer direction.

A change of colour and curve definition can appear in the transfer of vector data. Changes of font, size, colour etc. are possible with text transfer. They are all visible and easily corrected. Changes during image transfer are more complicated. Changes are harder if not impossible to restore and are ignored in most cases.

In response to the increasing demand of modern society for higher quality, the graphic industry has been working on product quality and standardisation in all segments of the production.

It is possible to place an image into a document in two ways. First is the import into the document from a file. Second is a clipboard. Import is still prevailing and provides higher quality. However, modern production emphasizes simplicity and speed as important factors. A search for a faster and simpler methods of production is an ever going quest. Use of clipboard is one such way, even though it can influence the quality of the graphic product.

The adaptation of information almost always happens during image transfer through the buffer and it can result in the change of colour in the image. That change can be more or less visible depending on the data transfer direction and prevailing colours in the image.

Visual research established that the changes are more visible in certain motifs. Subjects spotted those differences more easily in motifs of the human face, sea and forest. Those motifs contain more details than for example winter motifs that contain less colour information.
The difference was easily spotted in the motif of human face and hardest in test samples with prevailing red colour.

Even though both instrumental and visual analysis confirm that the use of clipboard adapts data, the clipboard is commonly used because of its simplicity and speed.

In order to achieve a larger level of standardisation, the use of clipboard in professional purposes will require additional adjustments of operating systems and graphic tools.

\section{REFERENCES}

[1] Kipphan, H. (2014). Handbook of Print Media: Technologies and Production Methods. Springer Berlin Heidelberg.

[2] Pedersen, M., Bonnier, N., Hardeberg, J. Y. \& Albregtsen, F. (2009). Attributes of a New Image Quality Model for Color Prints. The $17^{\text {th }}$ Color Imaging Conference, Albuquerque, NM, USA, 204-209.

[3] Microsoft Developer Network, About the Clipboard 2016 $\mathrm{http}: / / \mathrm{msdn} . \mathrm{microsoft} . c o m /$ en-us/library/ms649012 (v=VS.85).aspx (01.07.2016)

[4] Microsoft Developer Network, Standard Clipboard Formats (Windows) n.d. https://msdn.microsoft.com/en-us/library/ windows/desktop/ff729168(v=vs.85).aspx (02.07.2016).

[5] Mac Developer Library, Pasteboard Concepts. Mac Developer Library 2016. https://developer.apple.com/ library/mac/documentation/Cocoa/Conceptual/PasteboardG uide106/Articles/pbConcepts.html\#//apple_ref/doc/uid/TP4 0008101-SW1 (02.07.2016)

[6] Mac Developer Library, Pasteboard Programming Guide. MAc OS X Developer Library 2016. $\mathrm{http} / / /$ developer.apple.com/library/mac/\#documentation/coc oa/Conceptual/PasteboardGuide106/Introduction/Introducti on.html\#//apple ref/doc/uid/TP40008100-SW1 (01.07.2016)

[7] Kuehni, R. G. (2003). Color space and its divisions: color order from antiquity to the present. Hoboken, $\mathrm{NJ}$ : WileyInterscience. https://doi.org/10.1002/0471432261

[8] Mikota, M. (2007). Studija sustava digitalne portretne fotografije. Doctoral thesis, Faculty of Graphic Arts,

\section{Contact information:}

mr. sc. Ivan PUČIĆ

Grafički fakultet Sveučilišta u Zagrebu Getaldićeva 2, 10000 Zagreb, Croatia

E-mail: ivan.pucic@grf.hr

\section{Dr. sc. Mile MATIJEVIC}

Grafički fakultet Sveučilišta u Zagrebu Getaldićeva 2, 10000 Zagreb, Croatia

E-mail: mile.matijevic@grf.hr

\section{Dr. sc. Nikola MRVAC}

Grafički fakultet Sveučilišta u Zagrebu Getaldićeva 2, 10000 Zagreb, Croatia

E-mail: nikola.mrvac@grf.hr 